\title{
Fetal Blood Loss
}

National Cancer Institute

\section{Source}

National Cancer Institute. Fetal Blood Loss. NCI Thesaurus. Code C113148.

Loss of blood from the fetal circulation. 